\title{
A Brief Discussion on the Buddhist Literature and Art of the Tang Dynasty
}

\author{
Wang Xiaohong \\ Weinan Normal University, College of Hunmanism, Weinan, Shaanxi, 714000
}

Keywords: The Tang Dynasty, Buddhism, Literature, Art

\begin{abstract}
While Buddhism developed rapidly in the Tang Dynasty, the Buddhist literature also gained an unprecedented development. As a representative of popular literature Bianwen and Zen poems are popular in the Tang dynasty. In addition, the Buddhist art of the Tang Dynasty has also developed further. Whether it is carving, painting, architecture or calligraphy, it has made great progress and has a profound influence on future generations.
\end{abstract}

\section{Introduction}

In the Tang Dynasty, accompanied by the tolerant religious and cultural atmosphere created by the times and the support and utilization of Buddhism by emperors, the development of Buddhism in China entered its prosperity and heyday [1]. At the same time, the literature and art of Buddhism have also been developed and widely spread.

\section{The Buddhist Literature of the Tang Dynasty}

In the feudal Tang Dynasty, Buddhism became more and more prosperous, the culture of Buddhism developed rapidly, and the Buddhist literature developed unprecedentedly. Buddhism popular literature in the most representative Bianwen is popular in the Tang dynasty.

At the beginning of twentieth Century, the Dunhuang Canon found nearly fifty thousand volumes of manuscripts. It provides rich and valuable documents for the study of ancient China, especially the Tang and Five Dynasties in terms of social economy, politics, history, geography, philosophy, literature, art, science and technology, language and so on. A large number of literary works in Dunhuang manuscripts, Bianwen is one of the important category of works [2]. The so-called Bianwen, is Buddhist scriptures popular rap literature, it is in the southern and Northern Dynasties (by chanting "reading"), Cozan ("service") form the basis and guide the publicity of Buddhist singing on a rap literature. In order to publicize Buddhism and make it easy for the public to accept Buddhist doctrines, Buddhist monks used the rap art that was prevalent in the Tang Dynasty to publicize Buddhist doctrines and read Buddhist tales [3]. "Change", "transfer" refers to the rap, and in the transformation of "change" and "change" in the collection of the meaning and origin of purple, has been the Chinese and foreign scholars try to interpret without a conclusion. However, it is noteworthy that Bianwen is a rap art, it can adapt to people's aesthetic taste, at the same time, also the influence of Buddhist literature. The introduction of Buddhism to China for Chinese, Vatican, save a lot of the original vocabulary, grammar and style; "twelve" inside the deed by repeating Argumentation Prose, Yingsong poetry focuses on the meaning of long, not long in poetry verse Gatha [4]. Doctrine style; the Buddhist missionary ways of the popularization of the Six Dynasties for example, sing, read, chant of praise to guide, go to the public, these are spawned in form of Bianwen and change.

Now save the Dunhuang Bianwen, according to the theme can be divided into four categories: one is the religious orders such as "dry Bianwen, even among the offerings to save the mother", "JiangMo Bianwen" eight phase ", Bianwen" etc [5]. This kind of Buddhist stories through Bianwen rap, basic teachings of Buddhism propaganda. They are different from the Scriptures. They often do not directly quote scriptures, but choose the most interesting stories in Buddhist scriptures, and then expand their narration, render them to play, and are seldom constrained by Buddhist scriptures. Two is the history of Bianwen, such as "Wang Zhaojun" and "Wu Zixu anthology" Bianwen etc [6]. 
Most of them are based on a historical figure, using anecdotes and anecdotes to absorb folklore and to render them. "Probably the history of events, which play a related condition; then more decorated, like with parallelism, a certificate in poetry, and miscellaneous in words, Bo laugh." For example, "Wu Zixu gently", it tells the story of Wu Zixu. Chuping Wang and Wu she killed, Wu Zixu fled to the king of Wu Chu Wu, help out after Wu Zixu for revenge; dare to admonish convicted, King Wu was killed. It is strongly praised the good character $\mathrm{Wu} \mathrm{Zixu}$, the fate of the brave, Kindness and hatred are clearly distinguished. In this kind of historical themes drawn from the Han Dynasty in the collection, the story is more. This kind of most of the performance of the local Bianwen yearning and nostalgia for the old [7-8]. In the situation of social confusion and the fall of the region at that time, the stories were sung with infinite emotion. The third category is the folklore theme is "Bianwen, Prince", "Liu Shun Zi shiko gently" etc. This kind of Bianwen borrow real historical figures to the interpretation of fictional history. The fourth category is based on the local time of major events and figures, such as "deep", "Zhang Huai Bianwen Zhang Yichao Bianwen" etc. This kind of Bianwen is now incomplete, it can still be seen in Bianwen content is in tribute to Zhang Yichao and his nephew of the GUI Yi army bravely against alien aggression and to protect our environment their heroic deeds [9].

The characteristics of Dunhuang Bianwen is rich in imagination, the plot twists and turns, vivid and lively language, easy for people to accept. As the change of Bianwen dibon, was originally used to allow artists to rap. Therefore, Bianwen often said table and chanting combination of narrative and endorsement and the use of literature, music and performance will be [10]. It is the most prominent feature of the art is to sound Teaser extremely rich interpretation of stories.

In the Buddhist literature of the Tang Dynasty, there was a striking phenomenon that was the prevalence of Zen poetry. The so-called Zen poetry, mainly refers to the expression of Zen philosophic and artistic conception or so-called "Zen" poetry. Because Zen and poetry are more emphasis on the experience and feeling of the heart, in the expression of the pursuit can sense and can only be sensed "illocutionary purpose", "the rhyme", which can be naturally combined together. As Yuan Hau asked in the poem of Songshan Juan waitress, "poetry is a Zen guest to add flower brocade, and Zen is a poem cutter." There are two kinds of authors in Zen poetry [11]. One is the literati and doctors who are closely related to Zen master and deeply influenced by Zen. They injected new meanings into Tang poetry by Zen.

Zen is "by means of non-literature phase advertised, emphasizing" koans "and", in the nature of Buddhahood upon en lightenment "understanding of the essence of the universe and life and their life background. In order to express the "unspeakable" It differs from man to man. Buddhist realm or inspire people from sel-enlightenment, Zen is often used in poetry, hymns and other forms, leaving a lot of valuable literary works. For example, for Zen three ancestral sengcan made "confidence Ming" feel "Yongjia, Yongjia", "Doha tau melt" heart clan Ming "and other works, read catchy and meaningful. Some sentence itself is a very beautiful poem, such as "the river, pine wind, clear night night what? The Buddha Xingjie to India, fog clouds body coat" [12]. The famous Tang Dynasty poem monk Wang Fanzhi, Hanshan, Jiaoran, picking up more is left a large number of Buddhist poems full of fun, to send people to the understanding on the dimension of "poem about": "the lake never wins the world, love alone is far. See a solitary space, a hydroscope transit." In the late Tang and Five Dynasties, Zen Zen master flourishing, between in eloquent quiz, often with the form of poetry.

During Zen meditation and Zen poetry, many famous poets in the Tang Dynasty were influenced by Zen. They also wrote many exquisite poems expressing Zen and Zen. They added splendour to Tang poetry. The most prominent of which is the "me" the reputation of Wang Wei, his landscape poetry is considered to be the best in the Zen poetry. For example, the famous "immortal" abattis: "no mountains, but hear a voice. King back into the deep forest, the moss on the." Another example: "bird stream "idle people fall osmanthus, quiet night spring hill [13]. Moonrise Yamadori shock, when Ming Chun jian." These poems, a few sentences, give the impression that the landscape of the natural scenery, deep and expressed Xuan Ji the corporation environment, a good man, from the Buddhist thought I two forget and non-attachment without easy, Zen philosophy of life. The 
ethereal, detached and indifferent implication as interesting, the so-called real words while indefinite. Liu Zongyuan's "Snow" is a Song Jiang full of Zen poetry, has always been popular: "Qianshan bird flew away, nobody trail. In Li Weng, fishing alone in snow." This kind of Zen poems accounted for a considerable proportion in the Tang dynasty. In under the influence of Zen Buddhism in the Tang Dynasty, began to appear in the combination of Zen and poetry theory point of view, to the Song Dynasty, Zen poetry, "Zen poetry" poetry theory is getting more popular. This theory has a considerable position and influence in the history of Chinese literary criticism.

\section{The Buddhist Art of the Tang Dynasty}

The Buddhist art in the Sui and Tang dynasties also developed further. The famous Dunhuang grottoes, Longmen Grottoes and so on have been further chiseled. In the Tang Dynasty was a big building in Longmen Grottoes, and as many as Amitabha and Buddha Maitreya, reflects the tendency of rise and grotto art of Buddhism of the secularization of Tang dynasty. China largest existing stone Buddhist stone from Fangshan, Salmonella in Youzhou static Wan Sui Motang began to hide [14]. Fangshan in Fangshan County of Beijing City, big mountain, hidden in the nine stone-mountain cave and yunjusi southwest of the crypt, the number and the moment for most of the Liao and Jin dynasties. Now the size of plate ten thousand 5000 block coexist, engraved with more than one thousand volumes of Buddhist scriptures, Sanqiansibaiyu. The Tang Dynasty statues have outstanding progress in realistic skills, many of them offer high hair, a thin skin clothes, its beautiful gesture, smiling eyes and mouth, full of human life, like Chinese beautiful women [15].

Sui and Tang Dynasties Buddhist painting based on further integration on the national tradition also reached its apogee, especially the mural is unprecedented, occupies an important position in the history of painting China. "EMI Zha" of the famous painter Wu Daozi, set the painter into the life, mainly engaged in temple mural creation, in Luoyang, Changan temple for Buddhist religious murals between 300. As mentioned earlier, due to the emergence of Sujiang popular rap Buddhist Bianwen in Tang Dynasty, with Bianwen developed, and create a lot of rich and colorful picture by variable [16]. The existing Dunhuang murals, a variety of Sutra paintings is the subject of the Tang Dynasty Sutra painting reached a very high artistic achievement, which is the main content of Amitabha, Maitreya pure land, and their statues of this period is consistent with the theme.

Due to the prevalence of Buddhist Zen Buddhism in the Tang Dynasty, the style of Buddhism, especially the transcendental artistic conception of Zen, had a profound influence on the traditional painting art. Wang Wei's painting and ink landscape style has changed the traditional landscape painting style has great influence on the later development of China painting. Dong Qichang said that Wang Wei is the Ming Dynasty landscape painting "southern" progenitor, said: "Zen home north and south two cases, Tang Shishi; painting of the north and south two, Tang also time, but its non-south ear. In the north is Li Sixun and his son spread for coloring the landscape, song Zhao Gan, Zhao Boju, Su Bo, and MA (far), summer (GUI) generation; Wang Mojie (Southern dimension) beginning with light, a hook chop of the law, the transfer to the bath, Zhang Jing (Ho), Guan Tong (), Dong (source), giant (of course), Guo Zhongshu, and his son (in meters and friends, four Yuan Ren) and people (Huang Gongwang, Wuzhen, Ni Zan, Wang Meng) [17]. As the sixth patriarch, a small horse, Cloud Gate, Rinzai son Sun Zhisheng, and in the North (micro)." Though Dong Qichang did not agree with the historical facts of the development and evolution of landscape painting and had the idea of "advocating south" and "depreciating the north", he affirmed the status of Wang Wei's influence on the creation of painting style, which is indeed consistent with reality.

The Buddhist architectural art in the Sui and Tang dynasties also reached a fairly high level. The Sui Dynasty temple in Daxingshan temple, East meditation temple, the most magnificent, especially the Eastern meditation temple, driving the seven storey tower with the clouds". The Tang Dynasty was built in Mount Wutai in the South Temple and the Buddhist temple, is China's oldest Buddhist temple. Sui and Tang Dynasties temple buildings, mostly in the temple as the center, changed the past to the pagoda as the main body of the general layout, the pagoda are placed next to the temple built in the other Tayuan but not in temples. The pagoda of the Tang Dynasty, which created the octagonal structure in form, changed from the past wood structure to the masonry structure on the 
material. Qixia mountain is located in the Nanjing suburb northeast of the stupa is a five layer eight side of the tower, the tower was built in the Sui Dynasty the first year (601 years), the rebuilt. Stone made of limestone and marble carved, elegant, fine carving. The first layer of the tower are carved four kings and Manjusri and Samantabhadra like other layers; each side cutting Fokan, sitting inside the small Buddha; under the roof slope engraved on the "flying" like a plump, very pretty and charming, and are very similar to Dunhuang flying [18]. In short, the spire is a set of architectural art and sculpture art in one of the fine art of Buddhism, it is Buddhism of the Sui and Tang Dynasties Five Dynasties Stone Art in Jiangnan as an important representative. In the Tang Dynasty, also began making a large number of Buddhist art unique architecture "column". Jycwhk is engraved Buddhist text or patterns on the pillar. Our general column is composed of a base, building body and building roof is composed of three parts, two tablets, such as at the end of the Tang dynasty built the famous Shanxi Mount Wutai Buddhist temple solemn simplicity, beautifully carved, precious works of art. The Buddhist architectural art of the Sui and Tang Dynasties added new treasures to the treasure house of ancient Chinese art.

The introduction of Buddhism also had a great influence on Chinese calligraphy. This influence is mainly reflected in two aspects. One is that Buddhist calligraphy has enriched Chinese calligraphy art directly, and the other is Buddhism, especially Zen's influence on calligraphy theory and calligraphy practice.

The Buddhist calligraphy described here mainly refers to the Scriptures, statues, and stone carvings, which are directly related to Buddhism. India Buddhism was introduced into China, which itself is not what the new form of calligraphy or theory, but the need for preaching missionary, Buddhism attaches great importance to and copied by the statues and other activities, and thus the formation of a unique Buddhist art of calligraphy. In Buddhism, there are ten kinds of method for the classic, known as the "ten law", namely, writing, listening and support, he applied, and uphold the curtain, and open a book and read, and the thought and practice, which is located in the first row of writing. After a multitude of Buddhism was introduced into China, the Buddhist China with pious attitude and skill of leaving a large number of calligraphy art treasures for us, and has produced many outstanding calligrapher monks in Buddhist scriptures in the writing process. At the end of the suichu Chen Zhi Yong Tang Huai Su and so is one of the best.

In addition, the Buddhist grottoes, which prevailed in the northern and Southern Dynasties and the Sui and Tang Dynasties, left many "statues" in the creation of a large number of exquisite sculptures. These kinds of inscription on the statues, most natural and simple, unique style, style and beauty also has the different states, constitute an important part of China Buddhist art of calligraphy.

The theory and practice of Buddhism, especially the Zen, had a great influence on the theory and practice of Chinese calligraphy. Since the late Tang Dynasty, under the influence of Zen Buddhism, many calligraphers came into calligraphy with Zen, regarded calligraphy as the way of Zen, and formed a unique calligraphy theory based on Zen theory and Zen book. Zen Buddhism has always been to "by means of non-literature" and "koans" flaunt, heavy mind against epiphany defending stereotyping or persistent words phase, under its influence, the theory of calligraphy also appeared heavy emphasis on Shangyi enlightenment. The five generation of painting monk Guanxiu (832-913) good cursive, he advocates the "take Huai Su chaos wipe no rules", that "I fear for grinding ink, mountain water, day and pen book Xi earth, but can show slightly mad monk." After the "Shang Yi" the book is very popular in Song dynasty. There is a close relationship between Shang and Yi. At the end of the Tang Dynasty Buddhism monks had light industry on Lu Xisheng, the strokes, with cursive, he made such celebrated for a time, the view of Calligraphy: calligraphy and Buddhism Koan, in the heart, in the enlightenment, preaching non mouth hand." In order to embody the way of calligraphy which is still meaning and reconsideration, many calligraphers emphasize on the lack of desire and pure mind when writing books, and ask for the creation of calligraphy with the interest of Zen Buddhism, and incorporate Zen into calligraphy, forming a unique style. 


\section{References}

[1] Rong C. An Analysis of the Confucian Ethicizing Features of the Buddhist Monks in the Tang Dynasty[J]. Journal of Taiyuan University of Technology, 2015.

[2] Feng J. A Research of Ding Kiln from The Inscriptions on The Stone Tablet in Memory of Late Buddhist Monk Hengyue of the Tang Dynasty[J]. Palace Museum Journal, 2013.

[3] Wang X, Zhao Y. "Painting” and “Carving” of the Buddhist Sculptures in Tang Dynasty[J]. Journal of Anshun University, 2015.

[4] Zhang C. The Interpretation of the Buddhist Poetry in Tang Dynasty: Solitary, Emptiness, Dilution[J]. Journal of Zhejiang Shuren University, 2013.

[5] Zhao Q, Zhao J, Ying-Cun L I, et al. An Investigation of the Medical Education and Health Care Condition in Dunhuang Area in Tang Dynasty Based on Medical Literature on Dunhuang [J]. Guiding Journal of Traditional Chinese Medicine \& Pharmacy, 2017.

[6] Meng F, Huang X. On The Stone Tablet with Inscription for Memorizing Late Buddhist Monk Hengyue of the Tang Dynasty_— The Late-Tang Ding Kiln Was Actually Supervised by Yiwu Army under The Tang Military Governor[J]. Palace Museum Journal, 2014.

[7] Zheng J, Jun-Lian F U. History of Early Studies on the Buddhist Poetry from the Dunhuang Caves[J]. Journal of China West Normal University, 2016.

[8] Fang X U, Literature S O, University S N. A Brief Discussion about Taoism, Buddhism, and Confucianism Embodied in Longyou Literature of the Tang Dynasty[J]. Journal of Lanzhou University, 2014.

[9] Yang Y. On the Religious Symbiosis in Tomb Art of the Tang Dynasty[J]. Journal of Nanjing Arts Institute, 2016.

[10] Fan K. The theme and function of figure painting in the Tang Dynasty[J]. Journal of Jilin University of Arts, 2015.

[11] Han J M. A Literature Research on the Establishment of Zen Buddhism Temple in Tang Dynasty of China[J]. 2015, 31(11):143-152.

[12] Wang Y D, Wang H Y, School F L. On the Deformation Motif in the Romances of Tang Dynasty and Buddhist Stories[J]. Jilin Normal University Journal, 2013.

[13] Chen Y C, Chinese D O, University F. A Revisit of the Time of Monk Xuanzang of the Tang Dynasty on a Pilgrimage for Buddhist Scriptures: Focus on Rhyme Style[J]. Fudan Journal, 2014.

[14] Chen N B, Literature S O. The Utility of the Tang Dynasty Taoism of the Complementary[J]. Journal of Yunyang Teachers College, 2016.

[15] Xu W. The Narration and Discussion About "Xian Tianhua " in the Tang Dynasty Palace Music[J]. Lantai World, 2016.

[16] Zhexi P, Ma J, University Y. From the History of three Kingdoms Look Silla and the Tang Dynasty Literature Exchange[J]. Contemporary Korea, 2016.

[17] Liang Q. The Inf uence of Tang Dynasty's Social Culture on the Statue of Longmen Grottoes[J]. Furniture \& Interior Design, 2017.

[18] Li X. Pharmacist-Monks in the Tang Dynasty: A Group of Mahayana Buddhist Followers and their Contributions to Chinese Buddhism[J]. International Journal of Social Science Studies, 2016, $4(8)$. 